archives

of thermodynamics

Vol. 37(2016), No. 3, 19-29

DOI: $10.1515 /$ aoter-2016-0017

\title{
Heat transfer in plate heat exchanger channels: Experimental validation of selected correlation equations
}

\author{
JANUSZ T. CIEŚLIŃSKI ${ }^{a}$ * \\ ARTUR FIUK ${ }^{b}$ \\ KRZYSZTOF TYPIŃSKI ${ }^{b}$ \\ BARTŁOMIEJ SIEMIEŃCZUK ${ }^{b}$
}

a Gdańsk University of Technology, Narutowicza 11/12, 80-233 Gdańsk, Poland

b SECESPOL Ltd., Warszawska 50, 82-100 Nowy Dwór Gdański, Poland

\begin{abstract}
This study is focused on experimental investigation of selected type of brazed plate heat exchanger (PHEx). The Wilson plot approach was applied in order to estimate heat transfer coefficients for the PHEx passages. The main aim of the paper was to experimentally check ability of several correlations published in the literature to predict heat transfer coefficients by comparison experimentally obtained data with appropriate predictions. The results obtained revealed that Hausen and Dittus-Boelter correlations underestimated heat transfer coefficient for the tested PHEx by an order of magnitude. The Aspen Plate code overestimated heat transfer coefficient by about $50 \%$, while Muley-Manglik correlation overestimated it from $1 \%$ to $25 \%$, dependent on the value of Reynolds number and hot or cold liquid side.
\end{abstract}

Keywords: PHEx; Wilson method; Correlations

\section{Nomenclature}
$A \quad-$ heat transfer area, $\mathrm{m}^{2}$
c - specific heat, $\mathrm{kJ} /(\mathrm{kg} \mathrm{K})$
C - constant in the Wilson plot approach

\footnotetext{
${ }^{*}$ Corresponding Author. E-mail: jcieslin@pg.gda.pl
} 


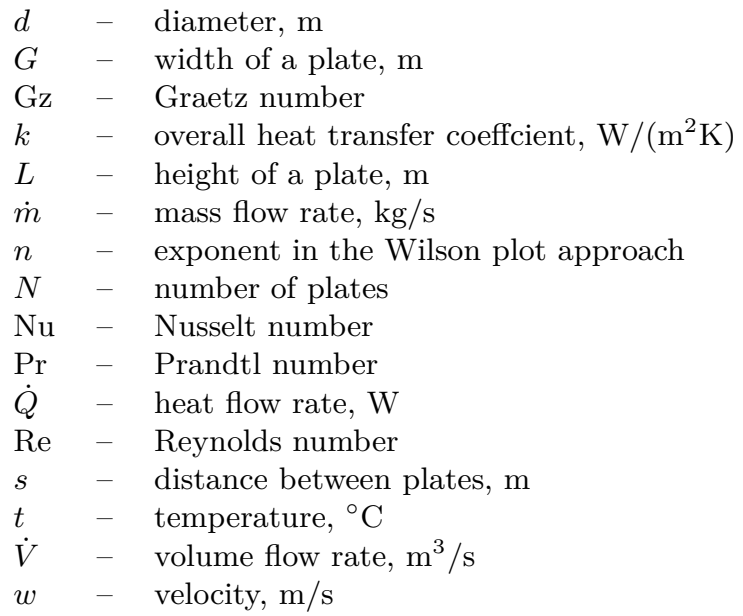

\section{Greek symbols}

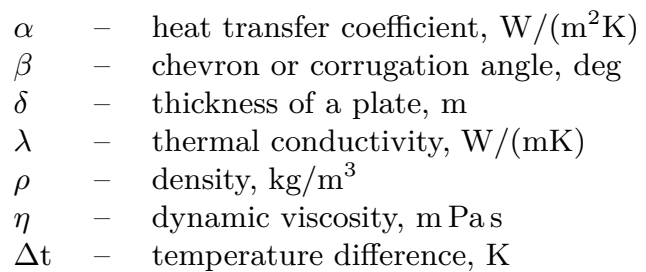

\section{Subscripts}

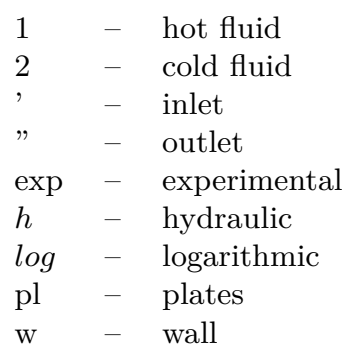

\section{Introduction}

A plate heat exchanger (PHEx) is a compact heat exchanger which provides many advantages and unique application features. These include flexible thermal sizing, easy cleaning for sustaining hygienic conditions, achievement of close approach temperatures due to their pure counter flow operation, and enhanced heat transfer performance.

The brazed plate heat exchanger consists of a pack of pressed plates 
brazed together, completely eliminating the use of gaskets, end frames, and bolts from the design. Instead, the plates are held together by brazing with copper under vacuum. This results in a much less complicated, lighter weight and more compact heat exchanger. Brazing of the corrugated, gasket-free plates together causes the two fluids to be directed through alternating channels between the plates. Their simple design also results in greatly reduced shipping and installation cost.

Apart from the above features, the brazed plate heat exchangers also have exceptional strength and durability. This is due to the fact that, in addition to sealing around the periphery of the plates, the internal contact points are also brazed together at thousands of contact points in each unit which admits them to operate at higher pressures and temperatures than gasketed units. The operating temperature of brazed heat exchangers ranges from $-195{ }^{\circ} \mathrm{C}$ to $350^{\circ} \mathrm{C}$, and their maximum operating pressure is 4.5 $\mathrm{MPa}$ [1]. However, today's new testing methods allow brazed units to operate up to $6 \mathrm{MPa}$ pressure conditions $[2,3]$. Recently, plate heat exchangers have found application in high temperature power system with solid oxide fuel cells [4].

The thermal-hydraulic performance of plate heat exchangers is strongly influenced by the plate surface corrugation patterns in the plate pack they are fitted with. Heat transfer plates are normally produced by stamping specially designed corrugations on the surface of thin metallic sheets. The corrugated plates used in plate heat exchangers can be manufactured from any metal or alloy that can be pressed, cold formed or welded.

When the plates are assembled in a stack, the corrugations on the adjoining plates form interrupted flow passages, and these intercorrugation flow paths promote enhanced convective heat transfer coefficients and decreased fouling characteristics. The corrugations also increase the effective surface area for heat transfer as well as plate rigidity, and the multiple metal-to-metal contact points between adjacent plates lend greater mechanical support to the stack.

The thermal-hydraulic design of plate heat exchangers is essentially similar to the general methodology employed for designing any other type of exchanger. The major design considerations may include:

- process/design or problem specifications;

- thermal and hydraulic design;

- mechanical/structural design, and operation and maintenance constraints; 
- manufacturing considerations and cost;

- trade-off factors and system-based optimization.

Extensive effort has been made in the past to experimentally investigate the heat transfer characteristics of plate heat exchangers. Data have been published for different types of chevron, herringbone and wash board plate heat exchangers [5-8]. However, the heat transfer enhancement characteristics of plate heat exchangers could be fully utilized in the industrial applications only if accurate correlations are available for Nusselt number and frictional pressure drop with all the necessary details. Although several single phase heat transfer correlations are available in the literature on plate heat exchangers [6,9-10], lack of data is still a kind of barrier in the use of plate heat exchangers in industry.

This study is focused on experimental investigation of selected type of brazed plate heat exchanger. The Wilson plot approach was applied in order to estimate heat transfer coefficients for the PHEx passages. The main aim of the paper was to experimentally validate Hausen [11], DittusBoelter [11] and Muley-Manglik [5] correlations by comparison experimentally obtained heat transfer coefficients with appropriate predictions. Additionally, commercial Aspen Plate code was used to determine heat transfer coefficients inside the PHEx channels [12].

\section{Experimental apparatus and procedure}

\subsection{Experimental facility}

The test stand - shown in Fig. 1, consists of four main systems: tested PHEx, heating water loop, cooling water loop and data acquisition system. Heating water flow rate was measured by Coriolis mass flowmeter of the type MASS2100 having an accuracy of $\pm 0.15 \%$ of the actual flow rate. Cooling water flow rates were controlled by a regulating valve and were measured by the Danfoss MAG 1100 magnetic flowmeter, which is accurate to $\pm 0.25 \%$. The average temperatures of the heating and cooling water at the inlets and outlets of the PHEx were measured using the Pt100 resistance temperature gauging device with an accuracy of $\pm 0.1^{\circ} \mathrm{C}$. The pressure drop of both cooling and heating water was measured by PELTRON of the type NPXD 1 pressure transducers accurate to $\pm 0.3 \%$. The volume flow rate of the cold water and hot water varied from $0.6 \mathrm{~m}^{3} / \mathrm{h}$ to $1 \mathrm{~m}^{3} / \mathrm{h}$. The 
temperature of the cold water and hot water varied from $40{ }^{\circ} \mathrm{C}$ to $64{ }^{\circ} \mathrm{C}$ and from $48^{\circ} \mathrm{C}$ to $72^{\circ} \mathrm{C}$, respectively.

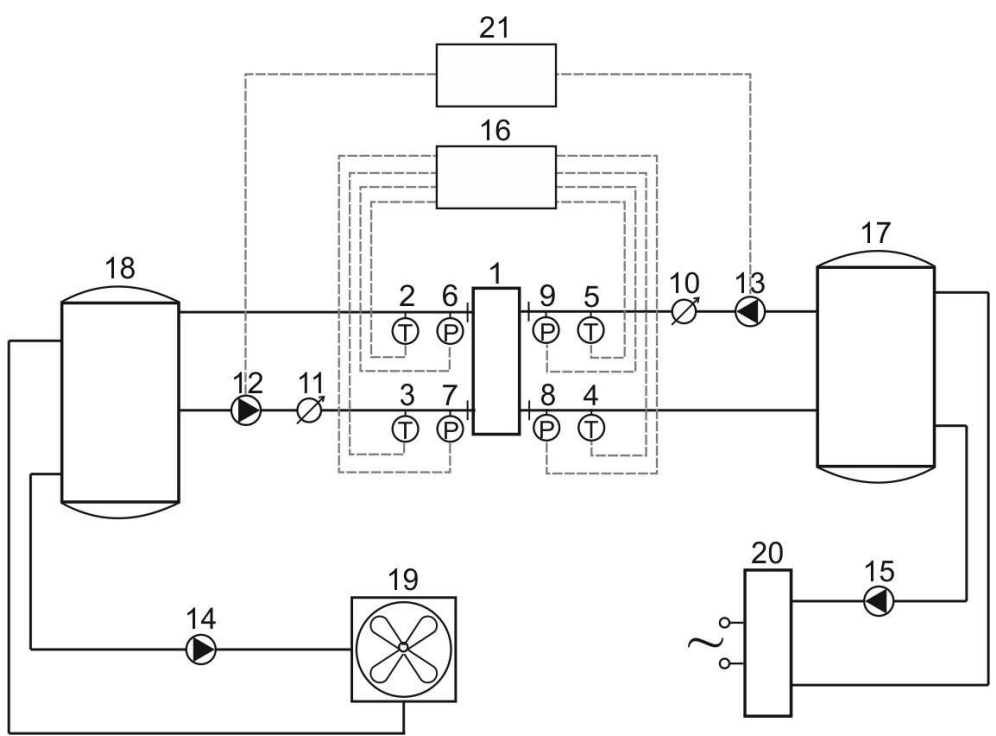

Figure 1: Scheme of the experimental setup: 1 - plate heat exchanger; 2,3,4,5 - thermoelements; 6,7,8,9 - pressure transducers; 10,11 - magnetic flowmeters; 12,13,14,15 - pumps; 16 - set of gauges; 17 - hot water tank; 18 - cold water tank; 19 - cooler; 20 - heating system; 21 - set of inverters; $\mathrm{T}$ - thermoelement; $\mathrm{P}$ - pressure transducer.

\subsection{Tested plate heat exchanger}

Experiments were carried out using a brazed plate heat exchanger (Fig. 2) type LA22-20 with commercial chevron plates made of stainless steel with chevron angle, $\beta$, of $61^{\circ}$ [13]. The characteristic dimensions of the plates were $0.08 \times 0.3 \times 0.0003 \mathrm{~m}$ with the distance between the plates, $\delta, 0.002 \mathrm{~m}$. The surface area of the tested PHEx was equal to $A=0.418 \mathrm{~m}^{2}$ while the surface enlargement factor for all the plates was equal to 1.117. Plates were installed, providing two fluid streams in counter flow arrangement as shown in Fig. 2.

\subsection{Wilson plot method}

In order to estimate heat transfer coefficients on both sides of the wall separating fluid exchanging heat installation of thermocouples for measurement 


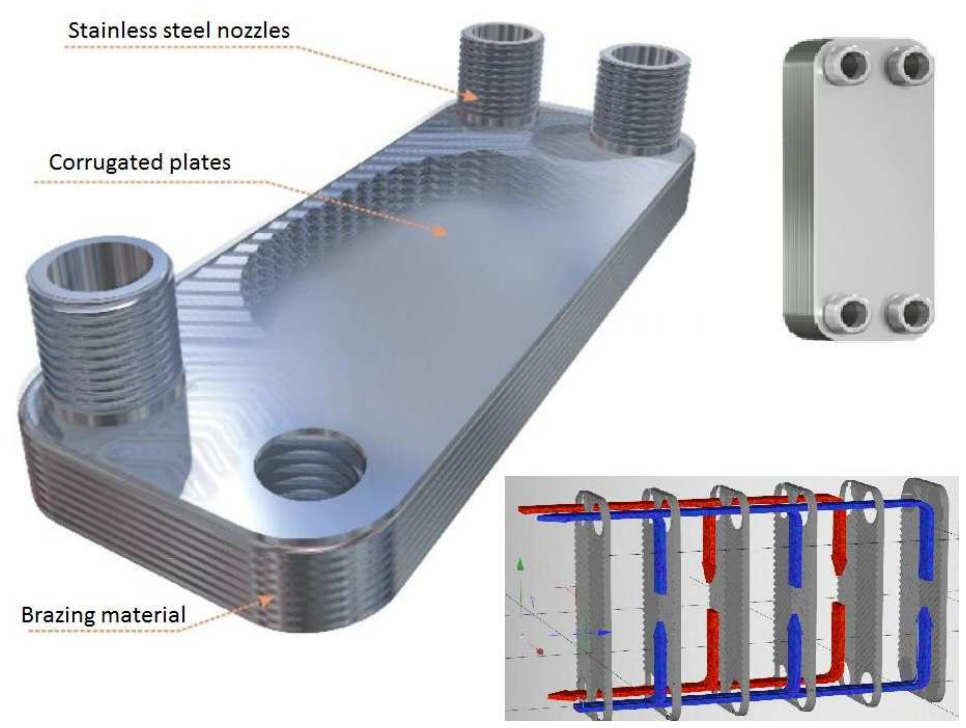

Figure 2: View of tested heat exchanger.

of wall temperature separating two fluids is required. If the recuperator has a complex geometry or as in present study is designed as a set of plates that are hermetically closed, then accurate measurement of the wall temperature faces significant difficulties. In such cases heat transfer coefficients can be predicted if the method due to Wilson plot is applied [14]. The method is simple and has a wide potential for applications of different types of heat exchangers [15-17]. The classical Wilson method, as well as its modifications, requires only determination of the overall resistance in the heat exchanger and hence an accurate energy balance, based on measurement of flow rates of fluids exchanging heat and their mean temperature at inlet and outlet from heat exchanger.

Assuming that the overall heat transfer coefficient is known and determined from the energy balance in the form

$$
k_{\exp }=\frac{\dot{Q}}{A \Delta t_{\log }}
$$

where heat flow rate reads

$$
\dot{Q}_{1}=\dot{m}_{1} c_{1}\left(t_{1}^{\prime}-t_{1}^{\prime \prime}\right)=\dot{Q}_{2}=\dot{m}_{2} c_{2}\left(t_{2}^{\prime \prime}-t_{2}^{\prime}\right) .
$$


The logarithmic mean temperature difference is calculated as

$$
\Delta t_{\log }=\frac{\left(t_{1}^{\prime}-t_{2}^{\prime \prime}\right)-\left(t_{1}^{\prime \prime}-t_{2}^{\prime}\right)}{\ln \frac{\left(t_{1}^{\prime}-t_{2}^{\prime \prime}\right)}{\left(t_{1}^{\prime \prime}-t_{2}^{\prime}\right)}},
$$

and mass flow rate is equal to

$$
\dot{m}_{1}=\rho_{1} \dot{V}_{1}, \quad \text { and } \quad \dot{m}_{2}=\rho_{2} \dot{V}_{2} .
$$

The heat transfer coefficients for $\dot{m}_{1}=$ const. and $\dot{m}_{2}=$ var can be calculated as

$$
\alpha_{1}=\text { const., } \quad \alpha_{2}=C_{2} w_{2}^{n_{2}},
$$

where $\alpha_{1}$ and $\alpha_{2}$ are heat transfer coefficients for hot and cold water at relevant mass flow rate, respectively, $w_{2}$ is the cold water velocity and $n_{2}$ - coefficient depending on the convective heat transfer regime. In the case of turbulent flow inside passages $n=0.8$. For the case when $\dot{m}_{1}=$ var and $\dot{m}_{2}=$ const. heat transfer coefficients can be calculated as

$$
\alpha_{1}=C_{1} w_{1}^{n}, \quad \alpha_{2}=\text { const } .
$$

Constants $C_{1}$ and $C_{2}$ are determined using the linear regression method of the least squares method, where the squares of vertical distances between experimental points and a regression line are considered to find minimum value of squares. Knowledge of constants $C_{1}$ and $C_{2}$ enables determination, for the same series of investigations, of a one value of heat transfer coefficient $\alpha_{1}$ as well as a sequence of values for the heat transfer coefficient $\alpha_{2}$. The minimum value of the correlation coefficient was equal to 0.89514 .

\subsection{Methods of heat transfer coefficient calculation}

In [9] two correlations have been proposed for calculation of an average heat transfer coefficient in PHEx passages:

- Hausen correlation

$$
\mathrm{Nu}=3.66+\frac{0.0668 \mathrm{Gz}}{1+0.04 \mathrm{Gz}^{2 / 3}},
$$

where Graetz number is defined as

$$
\mathrm{Gz}=\operatorname{RePr} \frac{d_{h}}{L},
$$


- Dittus-Boelter correlation

$$
\mathrm{Nu}=0.023 \mathrm{Re}^{0.8} \operatorname{Pr}^{n},
$$

where exponent $n=0.4$ for fluid heating and $n=0.3$ for fluid cooling.

In this paper Muley and Manglik correlation [5]

$$
\mathrm{Nu}=C(\beta)\left(\operatorname{Re}^{0.728+0.0543 \sin [(2 \pi \beta / 90)+3.7]} \operatorname{Pr}^{1 / 3}\left(\eta / \eta_{w}\right)^{0.14},\right.
$$

where

$$
C(\beta)=0.2668-0.006967 \beta+7.244 \times 10^{-5} \beta^{2}
$$

was tested as well, where $\beta$ represents chevron angle. Reynolds number is calculated as

$$
\operatorname{Re}=\frac{w d_{h} \rho}{\eta},
$$

where hydraulic diameter $d_{h}=s_{p l}$, and $s_{p l}$ is the distance between plates. Average velocity in PHEx passages reads

$$
w=\frac{\dot{m}}{G s_{p l} \rho N_{z}},
$$

where $N_{z}$ is the number of cold or hot passages.

\section{Results and discussion}

Figure 3 shows the comparison of the average heat transfer coefficient for hot water passages, for the case when $\dot{m}_{1}=$ const. and $\dot{m}_{2}=$ var. It is seen in Fig. 3 that Hausen correlation and Dittus-Boelter correlation dramatically underpredict values of the average heat transfer coefficient, while the Aspen Plate code overestimates heat transfer coefficient by about 50\%. Only Muley and Manglik correlation Eq. (10) predicts the heat transfer coefficient reasonably well. The discrepancy between the predictions and experimental results obtained by use of Wilson method does not exceed $10 \%$.

Figure 4, in turn, shows the comparison of the average heat transfer coefficient for cold water passages, for the case when $\dot{m}_{1}=$ var and $\dot{m}_{2}=$ const. Similarly as for hot water side, Hausen and Dittus-Boelter correlations dramatically underpredict values of the average heat transfer coefficient - even by an order of magnitude, while the commercial Aspen Plate code overestimates heat transfer coefficient by about 10\%. Again, 


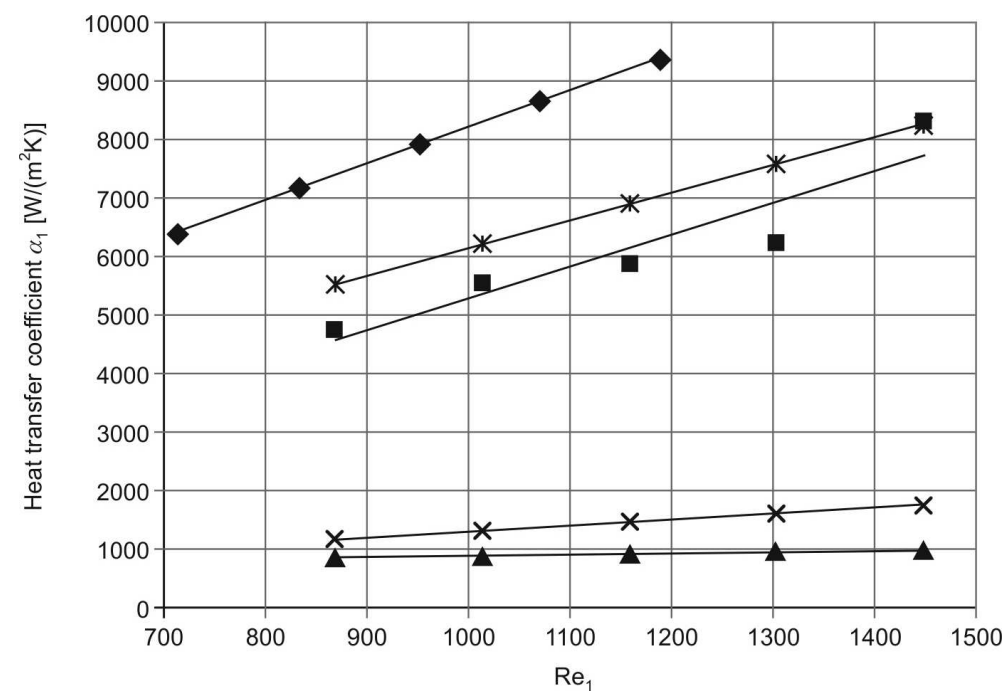

Figure 3: Hot water side heat transfer coefficient; $\boldsymbol{\Delta}$ - Eq. (7), x - Eq. (9), * - Eq. (10), $\checkmark$ - Aspen Plate code - Wilson approach.

only Muley and Manglik correlation Eq. (10) predicts the heat transfer coefficient reasonably well. The discrepancy between the predictions and experimental results obtained by use of Wilson method does not exceed $30 \%$.

\section{Conclusions}

The study revealed that proper selection of the correlation equation for heat transfer coefficient estimation in hot and cold passages of the PHEx is of primary importance in correct choice of plate heat exchanger. Particularly:

- Hausen and Dittus-Boelter correlations are not recommended to be used in calculation of heat transfer coefficient in passages of PHEx. It is necessary to remember, that Hausen and Dittus-Boelter correlations have been originally developed for forced convection in straight smooth tubes. It is possible to use both correlations for channels with different cross sections using equivalent (hydraulic) diameter. However heat transfer in small passages between plates is enhanced by strong local turbulence resulting from corrugations. Therefore both correlations dramatically underestimate values of heat transfer coefficients in passages between corrugated plates. 


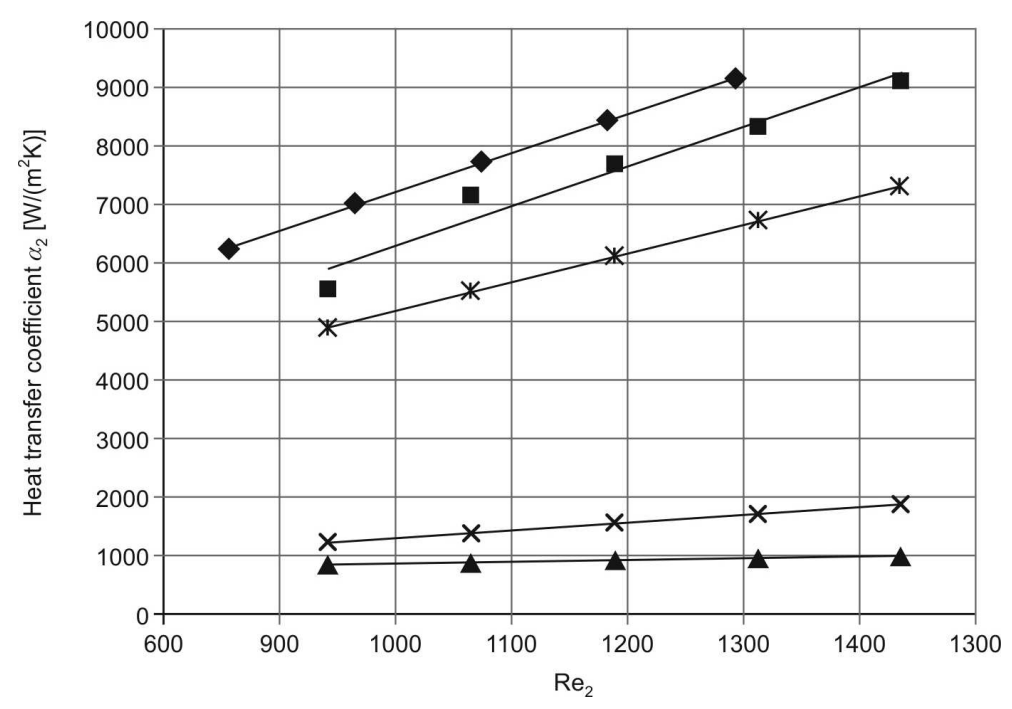

Figure 4: Cold water side heat transfer coefficient; $\boldsymbol{\Delta}$ - Eq. (7), x- Eq. 9), * - Eq. (10), $\checkmark$ - Aspen Plate code,

- Wilson approach.

- Present data show that in order to accurately estimate heat transfer coefficient in passages of PHEx, correlation equation specially dedicated for such sophisticated geometry should be applied. Particularly, such correlation equation should contain details of the plate geometry, like chevron or corrugation angle, corrugation depth, mean channel spacing or corrugation pitch.

- Wilson plot method seems to be a reliable tool in examination of plate heat exchangers.

\section{References}

[1] Wang L., Sunden B. And Manglik R.M.: Plate Heat Exchangers: Design, Applications and Performance. WIT Press, Southampton 2007.

[2] Alfa Laval, Product Catalogue, Sweden (http://www.alfalaval.com).

[3] SWEP International, Product Catalogue, Sweden (http://www.swep.net).

[4] Motyliński K., Kupecki J.: Modeling the dynamic operation of a small fin plate heat exchanger - parametric analysis. Arch. Thermodyn. 36(2015), 3, 85-103, 20836023. DOI: 10.1515 /aoter-2015-0023 
[5] Mulley A., Manglik R.M.: Enhanced thermal-hydraulic performance optimization of chevron plate heat exchangers. Int. J. Heat Exchangers 1(2000), 3-18.

[6] KHAN T.S. et al.: Experimental investigation of single phase convective heat transfer coefficient in a corrugated plate heat exchanger for multiple plate configurations. Appl. Thermal Eng. 30(2010), 8-9, 1058-1065.

[7] Jogi Nikhil G., Lawankar Shailendra M.: Heat transfer analysis of corrugated plate heat exchanger of different plate geometry: A Review. Int. J. Emerging Technol. Adv. Eng. 2(2012), 10, 110-115.

[8] Wajs J., Mikielewicz D.: Effect of surface roughness on thermal-hydraulic characteristics of plate heat exchanger. Key Eng. Materials 597(2014), 63-74.

[9] Lin D.T.W. et al.: The otimal design process of the plate heat exchanger. In: Proc. Int. Symp. Computer, Communication, Control and Automation, 2010, 978-1-42445567-6/10/@2010 IEEE.

[10] Niezgoda Żelasko B., Zalewski W.: Plate heat exchangers, Part I. Technika Chłodnicza i Klimatyzacyjna 170(2010), 4, 130-136 (in Polish).

[11] Wiśniewski S., Wiśniewski T.: Heat Transfer. WNT, Warszawa 1994 (in Polish).

[12] http://www.aspentech.com/products/aspen-plateplus.aspx

[13] http://www.secespol.cz/en/produkty/vymeniky/deskove-pajene/la22-2/la22-20-2/

[14] Mikielewicz J.: Determination of heat transfer coefficients for recuperators by use of the Wilson method. Technika Chłodnicza i Klimatyzacyjna 10(2001), 387-388 (in Polish).

[15] Mikielewicz D., Wajs J., Mikielewicz J.: Determination of heat transfer coefficient in evaporator of the ORC using the Wilson method. In: Proc. 17th Int. Conf. Heat Transfer and Renewable Sources of Energy, Szczecin-Miedzyzdroje 2008, 489-496.

[16] Shokouhmand H., Salimpour M.R., Akhavan-Behabadi M.A.: Experimental investigation of shell and coiled tube heat exchangers using Wilson plots. Int. Comm. Heat Mass Transfer 35(2008), 1, 84-92.

[17] CiEŚLIŃsKi J.T.: Effect of nanofluid concentration on two-phase thermosyphon heat exchanger performance. Arch. Thermodyn. 37(2016), 2, 23-40. 